\title{
BUENOS AIRES EN AMALIA: LA CIUDAD DESIERTO
}

Durante el crítico período de la dictadura rosista, los escritores románticos argentinos ${ }^{1}$ se interesaron no sólo por analizarla sino también por interpretar literariamente la condición de la ciudad de Buenos Aires bajo la tiranía.

La antítesis de lugar, la ciudad opuesta al campo, que Sarmiento formula como "civilización vs. barbarie", intenta encontrar la esencia de la realidad y fijar en dos corrientes la complejidad de intereses, doctrinas, sentimientos y fuerzas que estuvieron en juego durante la primera mitad del ochocientos. Sin embargo, la decidida dicotomía sarmicntina hace olvidar el esfuerzo intelectual y vital de la generación del 37 y de los intelectuales vinculados a ella, denuedo que no se limitó a tratar de comprender la realidad argentina, sino que procuró también planificar intentando incluir los aspectos del país que los doctrinarios de Mayo, por inexperiencia e idealismo, habían dejado de lado.

${ }^{1}$ Véase, por lo que respecta al romanticismo en Latinoamérica el artículo de B. Subercaseaux sobre Lastarria en el que se destaca la paradoja de los literatos liberales latinoamericanos del siglo XIX: "el haberse propuesto desarrollar una literatura propia, teniendo que partir, obligadamente, de una tradición literaria ajena. O para decirlo de otra manera: el haber sido consumidores no europeos (sin Revolución Francesa y sin Desarrollo Industrial) de una cultura europea" (B. Subercaseaux, "Romanticismo y liberalismo en el primer Lastarria", RevIb 47, 1981, p. 311). El crítico chileno, además, problematiza la caracterización de romántico cuando este término abarca fenómenos ideológicos y extraliterarios. Sin embargo, si esta distinción es fundamental para mejor comprender la literatura romántica de nuestro continente, la verdad es que, para la segunda generación de proscriptos argentinos, los límites entre la literatura y lo ideológico-político no estaban claramente definidos. E1 proyecto de "americanismo literario" fue, quizás, el más vinculado con un específico campo artístico. Del resto, a lo largo de las numerosas polémicas 
Sarmiento consideraba que las costumbres urbanas eran la suma de textos sobre los que se quería fundar la existencia del país; su idea era que de la difusión de las costumbres ciudadanas iba a derivar, casi naturalmente, un conjunto de reglas que lo organizasen. Alberdi, en cambio, tendía a fundar una cultura gramaticalizada - para usar la terminología de Lotman: importaban las leyes para ordenar lo caótico, y esas normas debían servir a toda la comunidad argentina. El pensamiento político de Echeverría es otra demostración del anhelo de los proscriptos por comprender el enigma de la realidad social. Como punto de partida, el autor del Dogma quería abarcar tanto las leyes como las costumbres y el estado social del país. Logra literariamente su aliento de síntesis en El matadero, en la representación de una cultura suburbana constituida por gente del campo que, aunque actuaba en forma mucho más beligerante que las masas rurales desperdigadas por la pampa, ya participaba de algunas usanzas ciudadanas.

Fue problemático, por cierto, el que los liberales argentinos vieran a la gente de la campaña como una "alteridad" opuesta a la civilización ${ }^{2}$ y, sobre todo, el que algunos de ellos no supieran reconocer - y es el caso de José Mármol, católico, conservador y rivadaviano- que los fenómenos que ocurrían fuera de los límites de la ciudad - y durante la época de Rosas, dentro de la misma Buenos Aires - era una "otredad" respecto de nuestra "civilización", pero que eran propios frente a Europa ${ }^{3}$.

entre neoclásicos y románticos (Varela-Alberdi), entre rosistas y románticos unitarios (recuérdense las sátiras de Pedro de Angelis) y las discusiones acerca de la esencia y la pertenencia al romanticismo (Vicente F. López Sarmiento) es posible verificar la imprecisa delimitación entonces existente entre literatura y política. Dejando de lado los "Estudios literarios." de Echeverría (Prosa literaria, Estrada, Buenos Aires, 1944) —en los que el escritor señala la urgencia de ofrecer un conjunto de signos que permita desvincular los recursos expresivos americanos de la tradición española, y donde reconoce la importancia de una armonía entre fondo y forma-, el resto del grupo proscripto veía a la literatura con una "función" menos estética y más política (Alberdi consideraba, por ejemplo, que la palabra era sólo un medio para la acción) y tendía a rechazar los aspectos "conservadores" del romanticismo, aquellos que no eran el vehículo más adecuado para expresar la ideología liberal (el concepto del arte desvinculado de la historia, y el de la preeminencia del individuo sobre la colectividad, los motivos medievales y católicos, etc.).

${ }^{2}$ Según Octavio Paz (Sor Juana Inés de la Cruz o Las trampas de la fe, Seix Barral, Barcelona, 1982, donde se extiende sobre la diacronía del concepto de “civilización"), "cada sociedad, al definirse a sí misma, define a las otras. Esa definición asume casi siempre la forma de una condenación: el otro es un ser fuera de la ley"' (ibid., p. 47).

${ }^{3}$ Les faltó la mirada antropológicamente abarcadora que poseyó el cuba- 
Esto determinó, en buena parte, el que la rotunda contraposición de Sarmiento se fijase en una fórmula en vez de evolucionar en un proceso dialéctico ${ }^{4}$ : desde el punto de vista políticoconceptual, se redujo la diversidad histórica en símbolos y arquetipos, interpretando con una forma los hechos, los que, a su vez, a lo largo del siglo irán estableciendo gradualmente el predominio de Buenos Aires sobre el resto del país. Pero, además, hay que decir que es Rosas el primero en utilizar en forma explícita un lenguaje contrastado e hiperbólico ("¡Vivan los federales! ¡Mueran los salvajes, asquerosos, inmundos unitarios! ¡Federación o muerte!'” $)^{5}$ y, a pesar de ello, es difícil negar la capacidad política y el realismo del gobernador de Buenos Aires. Es que, como señala J. L. Romero, "gracias a esta violencia, gracias a la habilidad con que manejó los instintos y las tendencias de las masas criollas, Rosas consiguió la aparente unanimidad de las opiniones a su favor[...]. Rosas consiguió infundir en el ánimo popular la convicción de que todos sus enemigos - entre los que había federales doctrinarios y muchos antiguos unitarios convencidos de las ventajas de la federación- constituían un solo grupo caracterizado por su centralismo irreductible y su extranjerismo anticriollo"6.

En las cabezas más destacadas de la segunda generación de proscriptos prevaleció un sentido más político que ideológico (trataron, en un primer momento, de acercarse a Rosas, para después hacerlo con Urquiza); sin embargo, antes de lograr una perspectiva conciliadora ${ }^{7}$, buena parte del grupo asumió la dicotomía

no José Martí para quien "el gobierno no es más que el equilibrio de los elementos naturales del país" (Páginas escogidas, Espasa-Calpe, Buenos Aires, 1953, p. 116).

${ }^{4}$ R. Morse piensa lo contrario: afirma que la dicotomía se dinamizó en una relación dialéctica que ayudó a moldear el desarrollo nacional. Cfi "The city-idea in Argentina. A study in evanescence", Journal of Urban History, 2 (1976), p. 308.

${ }^{5}$ La prioridad federal de dividir dualmente la sociedad, y en el momento en que ésta se mostraba como una amalgama más compleja que la de los tiempos de la Colonia, es también observable en códigos no verbales: “Bisogna comunque chiarire che erano stati i federali per primi a codificare a significazione dell' abigliamento imponendo l'uso di coccarde e nastri rossi come segno di fedeltà alla causa federale, e condannando frac, basetti e colore celeste quali segni di riconoscimento degli unitari", R. CAMPRA, "Il tiranno immaginario: Juan Manuel de Rosas. Tra storia e romanzo" en Storia di una iniquità, ed. P. L. Crovetto, Tilgher, Génova, 1981, p. 259.

${ }^{6}$ José Luis Romero, Las ideas politicas en Argentina, F.C.E., México, 1981, p. 126 .

${ }^{7}$ La prudencia y la conformidad ante el nuevo orden que se estaba ges- 
generada por la dictadura y la hizo suya ${ }^{8}$. Las formas antitéticas tuvieron para Rosas una función populista, pues le sirvieron para ajustar el antagonismo de las masas a sus intereses de terrateniente y al poder omnímodo que ejercía ${ }^{9}$; para los liberales significaron expresar el rechazo neto frente a las fuerzas que, neutralizando la oposición del pueblo, sólo miraban a su propia conveniencia y no a la de la nación en su totalidad. Esta aspiración genuina hay que enmarcarla dentro de una circunstancia: y es que todos los intelectuales del período pertenecen a la burguesía. Por eso, cuando se hablaba de contraponer una nación constitucional al poder de Rosas y de los caudillos, se hacía desde una perspectiva de clase $^{10}$, lo cual no elimina la verdadera urgen-

tando hicieron que Mármol transformara y suavizara los ataques a los federales en la reedición de Amalia de 1855, a pesar de que el escritor había declarado que si hubiese tenido que modificar los hechos históricos de la novela por cuestiones políticas no la habría reeditado. Cf. B. E. Curia, "Problemas textuales de Amalia de José Mármol"', Incipit, 1982, núm. 2, 61-81.

${ }^{8}$ C. Acutis analiza la dicotomía "civilización $v s$. barbarie", y lo hace desde el punto de vista de la "barbarie". Al mismo tiempo subraya el aspecto principal de esta operación divisoria: "esiste uno strumento collaudato, un principio che presiede da tempi remoti ogni discriminazione di carattere culturale: quello dell'indifferenziazione dei diversi, della loro inclusione in un unico sistema" ("Tra il silenzio e il urlo", en Storia di una iniquità, pp. 219-220). O sea que, durante el momento crítico de la dictadura, tanto los grupos conservadores ligados a la tierra como los intelectuales pequeñoburgueses de matriz liberal afirman su identidad política negando las diferencias existentes en el grupo de la oposición. Conservadores y liberales se alían en una práctica, a mi modo de ver, reaccionaria.

"He tenido en cuenta la definición que de "populismo" da E. LACl.AU en "Hacia una teoría del populismo", en Politica e ideología en la teoría marxista, Siglo XXI, Madrid, 1978, pp. 165-233. Según Laclau, ciertos conceptos como "nacionalismo" o "populismo" históricamente han sido articulados a discursos políticos de significación diversa. Lo que importa es diferenciar el contenido de los niveles ideológicos y políticos, de la forma de existencia de las clases. Un principio reduccionista tiende a identificar ambos problemas; esto confunde, pues ciertos contenidos, según Laclau, no tienen connotación clasista. Conviene concebir la presencia de la clase en los niveles ideológico y político, no por los contenidos que éstos presenten sino por su forma, es decir, por el principio articulatorio específico que caracteriza a la clase. Aunque dos grupos - la clase burguesa o el movimiento comunista- presenten contenidos comunes (por ejemplo el "nacionalismo" de la clase burguesa, contra el particularismo feudal; o el "nacionalismo" vinculado con el socialismo en la China de Mao), sus esfuerzos articulatorios son antagónicos. En el caso que tratamos, se puede afirmar que "el nacionalismo" del gobierno rosista articuló el antagonismo independentista de las masas con los intereses terratenientes.

${ }^{10}$ La idea de la democracia en la República Argentina se desarrolla lentamente. A lo largo del siglo diecinueve es un concepto más vinculado a una 
cia, entonces existente, por ordenar lo que se veía como caótico, y reglamentar con un sentido mediato el problema de la concentración absoluta e individual del poder, que da lugar al abuso del mismo.

En las imágenes que representa Buenos Aires en la obra de los proscriptos se advierte un doble gesto referencial que indica dos cosas: "esta realidad particular que rechazo" y "esta realidad a la que aspiro". Así el referente concreto - del cual las obras pretenden constituir un $\alpha v \alpha \lambda o \gamma o v-$ es rechazado, mientras que el de índole político-filosófica es utópico. Es evidente que, si para constituir la imago del segundo se procede negando la del primero, se termina creando una contradicción que da lugar a una imagen urbana despedazada en una especie de patchwork estilístico, a un modo de representación dividido que responde al hecho de que dentro de una misma cultura existían campos semánticos contradictorios.

Entre los distintos textos de los románticos argentinos me interesa ahora analizar Amalia ${ }^{11}$ (inspirada en los acontecimientos de 1840 para describir la situación vivida bajo la dictadura de Rosas), ya que es el que presenta la visión más amplia y detallada de lo que era Buenos Aires a mediados del siglo pasado.

La estructura formal de la novela, que rige tanto la configuración de los personajes y las relaciones sociales de los mismos, como la función paradigmática de algunos elementos dentro del melodrama, es la antítesis. Todos los niveles del texto aparecen organizados coherentemente en función de una tesis interpretativa de la realidad urbana bajo la tiranía. Importa, pues, observar de qué manera diversos aspectos del tema ciudano remiten a los

ideología política - la liberal - y a una clase — la minoría ilustrada - que a un mecanismo de participación de la colectividad. Los liberales del 37 atacaron el sufragio universal que, paradójicamente, había sido instalado por aquellos unitarios que más tarde se encerrarían en un conservadurismo aristocrático. Echeverría afirmaba que "el derecho de sufragio, diferente del derecho individual anterior a toda institución, es de origen constitucional, y que el legislador puede, por lo mismo, restringirlo, amplificarlo, darle la forma conveniente" (Dogma socialista: ojeada retrospectiva, en La cautiva. El matadero y otros escritos, CEAL, Buenos Aires, 1967, p. 90). La democracia no era el despotismo absoluto de las masas sino el "régimen de la razón" que los del 37 ponían en manos de una élite ilustrada; por lo tanto, el sufragio universal consistía en entregar el país a la muchedumbre, a la parte rural del país, en donde perduraba la tradición hispano-criolla y una visión autoritaria del mundo; de allí que propusieran la soberanía sólo para la ciudad.

${ }^{11}$ José Mármol, Amalia, Porrúa, México, 1971. Las citas en el texto siguen esta edición. 
dos referentes mencionados - el objetivo y el utópico- para tratar de establecer el vínculo simbólico entre la realidad ciudadana de la primera mitad del siglo XIX y la imagen de Buenos Aires en la novela de Mármol ${ }^{12}$.

\section{LA VIDA COTIDIANA EN LA ALDEA PINTADA DE ROJO}

Amalia nos ofrece, en primer lugar, una imagen de Buenos Aires que se basa en datos físicos y geográficos. El espacio suburbano es el lugar de residencia de la protagonista; allí se dirigen los personajes que buscan refugio o pretenden su ayuda:

Daniel hacía marchar al paso su caballo. Llegó por fin a la calle de la Reconquista, y tomó la dirección a Barracas; atravesó la del Brasil y Patagones y tomó a la derecha por una calle encajonada, angosta y pantanosa, y en cuyos lados no había edificio alguno sino los fondos de ladrillo o de tunas de aquellas casas con que termina la ciudad sobre las barrancas de Barracas (I, 2, p. 12).

Paulatinamente se descubre el verdadero lado humano de la ciudad, que no es el de los fantoches degradados de Rosas, ni el de la sublime perfección de los unitarios. Un estilo de vida, de vestir, de ornamentación de arquitectura, de recreación, de relación con los demás persiste en entrometerse en el sintagma de la narración, aunque después termine alterado por los violentos paradigmas de las descripciones antitéticas o las personificaciones abstractas de las alegorías.

Al comenzar el día en la ciudad porteña $(I, 8)$, todavía persisten claroscuros, como de crepúsculo, escondidos por las calles "espaciosas y rectas" y limitados por edificios cuadrados. De la descripción se infiere la simplicidad del trazado y de la arquitectura ${ }^{13}$. Aunque la pintura del amanecer esté algo recar-

${ }^{12}$ G. Segre, en su artículo "Tema / motivo" (Enciclopedia Einaudi, t. 14, Torino, 1981), expresa: "Propio della tematica [...] è di non staccarsi mai nettamente dall'esperienza vissuta. La eventuale minor quantità d'esperienza viene compensanta con una piú stretta connessione alla esperienza stessa, o col potenziamento delle sue estrincazioni"; y agrega "Il rapporto dell'invenzione con la realtà è un rapporto simbolico. È simbolica la capacità descrittiva del discorso, simbolica la rappresentatività conferita a individui, oggetti, luoghi e comportamenti immaginati: nel primo caso la simbolicità è inmmediata, nel secondo essa non rinvia a referenti reali, ma ad una realtà dedotta da una generalizzazione di referenti (e di relazione tra referenti) affini"' (ibid, , p. 20).

${ }^{13}$ Henríquez Ureña observa que el desarrollo de las artes latinoamerica- 
gada de trazos rococó (el cielo tachonado de "nácares y oro"; la aurora que "se remontaba sobre su carro de ópalo"), hay una serie de precisos detalles que permiten reconstruir sensorialmente la atmósfera de esa madrugada sobre al aldea bonaerense. Las calles están inundadas por las intensas lluvias que cayeron durante el invierno de 1840. A pesar del lodo y de los espesos vapores húmedos que se han acumulado durante la noche, el alba trae consigo una brisa ligera. Buenos Aires se despliega ante nuestros ojos, se escucha el galope de los caballos por las calles empedradas y "el silencio de la ciudad era apenas interrumpido por el rodar monótono de algunos carros que se dirigían al mercado" (I, 8, p. 63).

A medida que el día avanza observamos lo cambiante del clima porteño (II, 2, p. 106): puede nublarse de súbito y sorprender el recreo de las diez en una escuela primaria; a esa misma hora el maestro almuerza un suculento puchero con huevos y café con leche (IV, 7, p. 280), mientras Amalia suele salir de un baño perfumado (II,1,p.100). A la una de la tarde los niños abandonarán la escuela y los adultos irán a dormir una siesta que se extiende, en general, hasta las tres de la tarde, "hora, en invierno, en que los porteños no abandonan jamás su vieja costumbre de salir al sol, sean cualesquiera los sucesos que sus rayos alumbren" (IV, 7, p. 281).

Por la tarde, la gente gusta pasear por el Bajo a la sombra de las álamos que ornan la avenida, y allí los curiosos son atraídos por los ruidos de los cañonazos de la artillería de Rosas cuando alguna ballenera francesa, que de noche recibe emigrados, se acerca demasiado a la costa (IV, 7, p. 281). Llegan los cuatro y los cafés son invadidos por grupos federales que acostumbran reunirse en esos lugares para tomar té o ponche. En los días de fiesta es común ver a los porteños sentarse en una especie de confitería ambulante instalada en la vereda de la catedral. En ciertas ocasiones, su plácida charla se transforma en algarabía cuando, por descuido de algún cochero, un carruaje pasa sus ruedas por la acera (II, 6, p. 129). Algunos llevan lacayos que tienen "que habérselas con esos muchachos de Buenos Aires que parecen todos discí-

nas, durante los años postindependentistas, se contrajo debido a la disminuçón de la riqueza, y esto se vio particularmente en la arquitectura, con la excepción de Río de Janeiro ("Romanticismo y anarquía. 1830-1860", en Recopilación de textos sobre la novela romántica latinoamericana, Casa de las Américas, La Habana, 1978, p. 41). En Amalia la ciudad, desde el punto de vista arquitectónico, es modesta; sólo a finales de siglo, con la afluencia de capitales, la arquitectura porteña unirá a la función utilitaria, la estética, y funcionará como propaganda indirecta del nuevo régimen económico. 
pulos del diablo, y que se entretienen en asaltar a aquéllos y disputarles su lugar en lo más rápido del andar del coche" (II, 6, p. 129). Los vehículos urbanos son tirados por caballos y, junto con las carretas, suelen causar problemas de tráfico, a pesar de que Buenos Aires es apenas una pequeña aldea; por eso personajes con apuro, como Daniel Bello, parten " a gran galope para Barracas, tomando las peores calles de la ciudad para no encontrar obstáculos de tránsito" (III, 15, p. 234).

Un día, a las cinco de la tarde, un personaje nos ofrece la perspectiva de la aldea desde una terraza. Daniel, en la azotea de la casa de doña Marcelina, sita en el comienzo de la calle Cochabamba,

recorrió con una mirada de águila toda la extensión que descubría desde aquel punto [...]. Al frente de la casa [...] una hermosa quinta; al fondo, el hueco y las casuchas donde comienza la calle de San Juan; a la derecha unos cuartos en ruina; a la izquierda, una casa antigua y vacía que daba a la barranca y a la cual se abría una pequeña ventana en la cocina de la casa (II, 2, p. 107).

Al pasar por la calle Tucumán se percibe un intenso vaho perfumado; es que dentro del convento de las capuchinas, que está protegido por una reja de hierro regalada por Rosas, hay un extenso bosque de naranjos (IV, 6, pp. 276-277).

En Amalia, la todavía pequeña aldea sobre el Plata tiene ya lazos con el pasado y el futuro: algunas casas presentan "un respetable carácter de antigüedad"' (II, 3, p. 113), que recuerda a las que don Juan de Garay hizo construir en 1580; y los vientos del sur, que traen consigo un soplo fragante y sutil desde las praderas de Barracas, llenas de violetas y jazmines naturales (I, 8, p. 61), comienzan a constituir esa futura atmósfera mítica, esos "buenos aires" que perdurarán en la memoria de los enfervorizados habitantes de Santa María de los Buenos Aires ${ }^{14}$.

${ }^{14}$ Es casi seguro que el nombre de la ciudad, "Nuestra Señora Santa María de los Buenos Ayres", fue dado en honor de la virgen Santa María Bonaria, patrona de los navegantes sardos y cuya veneración se extendió por el Mediterráneo. Sin embargo, la primera explicación "literaria" del nombre -y a ella me remito - la da UlRico SCHMIDEL: "Allí levantamos una ciudad que se llamó Buenos Aires: esto quiere decir buen viento" (Viaje al Rio de la Plata, en Los fundadores. Antología, ed. Canal Feijóo, CEAL, Buenos Aires, 1967, p. 7). 
RECURSOS ESTILÍSTICOS: OPOSICIONES Y ALEGORÍAS

Una de las primeras imágenes de Amalia es el espectáculo de Buenos Aires desde el Río de la Plata ("Pero argenteaba con él [Río de la Plata] las torres y chapiteles de esa ciudad a quien los poetas han llamado "La Emperatriz del Plata" o la "Atenas", o la "Roma del Nuevo Mundo»" (I, 8, p. 61). El párrafo parece sugerir la presencia de un observador que ve la costa desde una ballenera; este ángulo de visión concuerda con toda la estructura de la novela.

El narrador, aunque muestra pocos elementos físicos de la aldea ("torres", "chapiteles"), vincula ésta con ciudades de histórica relevancia, tal como lo hicieron los poetan neoclásicos porteños mientras vivían la llamada "feliz experiencia" de Buenos Aires bajo el ministerio de Rivadavia ${ }^{15}$. Pero las alabanzas del relator hacen también a una realidad: es la emperatriz del Plata porque gobierna y controla el río; es Atenas o Roma, porque centraliza, además, la cultura y la civilización. Esa nomenclatura remite a una tradición literaria argentina, pero se enlaza, asimismo, con la aspiración de Mármol — vuelto hacia Europa, ávido de modelos culturales- que veía en Buenos Aires el centro desde donde habría debido irradiarse el prestigio de una política unitaria.

En el capítulo VIII de la primera parte, observamos cómo amanece. El narrador introduce una personificada alba rococó que, con su luz, pone de nuevo en evidencia el horror de la vida de la aldea bajo el gobierno federal:

La blanca luz de esa beldad pudorosa de los cielos que asoma

${ }^{15}$ En la poesía neoclásica posterior a la independencia, Buenos Aires aparece en imágenes celebratorias (así como en otros países se festejaba la gloria de Lima, Santiago, Montevideo): en el "Himno nacional argentino" de V. LÓPEZ y Planes, Buenos Aires es la ciudad líder en las luchas por la independencia latinoamericana: "Buenos Aires se pone a la frente / de los pueblos de la ínclita unión / y con brazos robustos desgarran / al ibérico altivo León". Por otra parte, campo y ciudad se contraponen como en una geórgica, en "Oda al pueblo de Buenos Aires" de Esteban De LuCA. El poeta más conocido de la época rivadaviana, Juan Cruz VARela, no escatima alabanzas a Buenos Aires, que entonces sobresale por sus progresos administrativos y sus numerosas actividades culturales. En honor de la ciudad escribe "Canción": Buenos Aires es la tierra generosa de la libertad, donde "los libres del mundo a millares / agolpados se ven acudir", pues allí "encontraron las leyes su abrigo, / encontró la justicia su templo". Las citas de López y Planes y VARELA provienen de La lira argentina, ed. F. Rosenberg, CEAL, Buenos Aires, 1967, pp. 8 y 61 respectivamente. 
tierna y sonrosada en ellos para anunciar la venida del poderoso rey de la Naturaleza, no podía secar, con el ternísimo rayo de sus ojos, la sangre inocente que manchaba la orilla esmaltada de ese río, de cuyas ondas se levantaba, cubierta con su vuelo de rosas, su bellísima frente de jazmines (I, 8, p. 61).

En el contraste del rojo de la sangre que tiñe el río y la blancura de la luz del amancer, se incluye el leitmotiv del texto y, asimismo, su estructura folletinesca.

La aldea, como una figura recostada sobre la pampa, se niega a despertar. "Dormida sobre esa planicie inmensa en que reposa, Buenos Aires, la ciudad de las propensiones aristocráticas por naturaleza, parecía que quisiese resistir las horas del movimiento y de la vigilia que le anunciaba el día, y conservar su noche y su molicie por largo tiempo todavía" (I, 8, p. 61). Los elementos que configuran la imagen recuerdan la concepción volteriana de ciudad, en la que se aúnan la industria y el placer. Voltaire consideraba que la oposición entre pobres y ricos era la fuente de progreso del burgo. La personificación de Mármol presenta el lado mundano de la ciudad: se niega a despertar, como un sibarita que ha disfrutado las últimas horas de la noche. Hay frases claramente ideologizadas: "de las propensiones aristocráticas por naturaleza", para expresar los rasgos que él considera predominantes en Buenos Aires. Y esto también evoca a Voltaire, quien pensaba que de la burguesía dependía el intercambio social pero que, sin duda, la aristocracia era la delegada para hacer progresar las costumbres $^{16}$. No obstante estas semejanzas, el conservadurismo de Mármol posee una rigidez de visión que le hace rechazar, sobre todo, la movilidad social que Voltaire no impugnaba.

El contraste, con el que se abrió aquella imagen del amanecer sobre Buenos Aires, continúa como característica formal a lo largo de toda la novela. Las series de oposiciones, cuyos términos se entrelazan unos con otros, acaban por constituir paradigmas que estilísticamente se resuelven, muchas veces, en alegorías. Por ejemplo, en aquella época Buenos Aires no podía ser imaginada sin Montevideo, refugio de tantos emigrados y base de operaciones de Inglaterra, Francia y la guerrilla de Garibaldi. En el caso de Mármol, "Al evocar a Buenos Aires desde Montevideo, la nostalgia de la ciudad vecina y a la vez lejana confiere a las estampas

${ }^{16} \mathrm{C}$. SCHORSKE, "The idea of the city in European thought: Voltaire to Spengler", en The historian and the city, eds. O. Handdlin and J. Burchard, MIT Press, Cambridge, 1963, p. 98. 
ese matiz de lirismo grato a los románticos"'17. Pero, además, la capital orientai no se configura si no es con la sombra (en ese período de terror) que Buenos Aires le hace. La relación dialéctica de estas dos ciudades, que será una constante en la literatura rioplatense ${ }^{18}$, se configura por primera vez en Amalia. En Montevideo se vive una atmósfera de progreso y de riqueza; 1840 fue la época de oro de la ciudad oriental que "estaba en sus quince años; bella, radiente, envanecida..." (IlI, 4, p. 186). El narrador personifica la aldea del otro lado del Plata como una muchacha joven, frívola, sólo atenta a los halagos de los poetas y de sus habitantes, incapaz de escuchar verdades severas sobre su vida futura (III, 4, p. 186). Es la imagen opuesta de Buenos Aires que, en la visión del escritor, está teñida de rojo, sometida a Rosas, invadida por la campaña y el horror.

A su vez, Buenos Aires es uno de los términos de la oposición ciudad-interior, y como tal adquiere otro sentido. Se le introduce como una encarnación del Bien acorralada por oscuras amenazas. "Buenos Aires es en la lucha y durante ese tiempo, lo que Dios en el universo; aquélla está y resplandece por todas partes[...]. Las provincias del Río de la Plata eran un ángel malo, cuyo influjo dañoso las perseguía como la sombra al cuerpo"' (IV, 8, p. 286). En esta imagen de trasfondo religioso - aceptado como la base común de toda alegoría ${ }^{19}$ - es aún más evidente la concepción dualista del pensamiento de Mármol.

Aunque algunos personajes lean a Byron, la campaña significa, para el narrador, territorio despoblado, porque "la soledad estaba allí como parte negativa o acción de la barbarie y el desierto y la tarea urgente de nuestros románticos fue la de poblar y educar' '20. En Amalia, Natura es un antagonista al que hay que dominar, y no aparece personificada o convertida en un concepto abstracto. Sólo una vez se la representa así en el texto: “Pero la Naturaleza parece hacer alarde de su poder, rebelde a las insinuaciones humanas, cuanto más la humanidad busca en ella al-

17 A. Pagés Larraya, "Buenos Aires en la novela", RUBA, 4 (1946), núm. 2, p. 256.

${ }^{18}$ Así Borges dirá en "Montevideo": "Eres el Buenos Aires que tuvimos, el que en los años se alejó quietamente. / Eres nuestra y fiestera, como la estrella que duplican las aguas" (Obra poética 1923-69, Emecé, Buenos Aires, 1972, p. 87).

19 Angus Fletcher, Allegory. The theory of a symbolic mode, Cornell University Press, Ithaca, 1975, p. 20.

${ }^{20}$ A. P.oggiano, "Proposiciones para una revisión del romanticismo argentino", RevIb, 41 (1975), p. 75. 
gima afinidad con sus desgracias"' (I, 8, p. 62). En lugar de avenirse con la tristeza de los personajes, permanece "indiferente a las desgracias que se acumulaban sobre la cabeza de ese pueblo inocente..." (id.). Es que la pampa argentina es identificada poéticamente con los federales, con los gauchos de la Mazorca. No se la configura por medio de alegorías porque el narrador no la identifica con "madre natura", fuente de riqueza y abundancia, sino con el origen de la devastación. Las alegorías de Buenos Aires (Montevideo se constituye con el mismo procedimiento retórico) son de tipo situacional más que tipológico, porque el autor siente que sus lectores comparten su situación y la perciben como él ${ }^{21}$. La figura femenina en que se sintetiza Buenos Aires es, en resumidas cuentas, el proyecto de nación.

\section{LOS PERSONAJES Y SUS RELACIONES SOCIALES}

En Amalia la Buenos Aires ideal está representada en los unitarios, en sus lazos amorosos, en sus vínculos políticos, en el trato con sus criados; resulta difícil distinguir un retrato verosímil entre los unitarios extremadamente idealizados, pero es factible establecer su pertenencia de clase: tanto Eduardo como Amalia pertenecen a la pudiente, mientras que los personajes unitarios retratados humorísticamente - don Cándido y doña Marcelinason de origen pequeñoburgués.

En el ápendice de la represión, buena parte de las familias unitarias se desintegran porque sus miembros emigran, son muertos o aprisionados por la Mazorca o bien a pasan a constituir las filas de la Guardia de Luján. Para los unitarios la ciudad es una especie de cementerio de vivos: "[T] ción pendiente del menor ruido; las miradas cambiándose; el corazón latiendo" (V, 1, p. 334). El clima de terror acorrala a los grupos que viven pendientes de escapar a Montevideo o de la lle-

${ }^{21}$ A menudo el autor introduce al lector en la escena y le invita a moverse con él por la ciudad: "Salgamos del baile con el lector y vayamos un momento a recoger los pormenores de otra escena bien diferente" (II, 7, p. 140). El narrador apela a un lector virtual que posee las mismas actitudes ideológicas y sentimentales; se dirige, pues, a un compañero de camino. Por otra parte, este artificio es uno de los rasgos estructurales del folletín y tiene que ver, además, con toda la novela centrada alrededor de un espacio: en su composición se buscan recursos que desplacen, con el "volumen" del lugar figurado, el sitio real en el que se encuentra el lector. En relación con esto último, cf. M. BuTor, 'L'espace du roman', en Répertoire III, Éditions de Minuit, Paris, 1964, pp. 42-50. 
gada de Lavalle. Un personaje de interés, desde el punto de vista literario - ya por su función dentro de la misma novela, ya por el antecedente que constituye-, es Daniel Bello. Como por ese entonces en Buenos Aires no se permite el diálogo, Bello se enmascara de federal. Este uso del "disfraz" - en este caso para sobrevivir en una ciudad reprimida - será la principal característica de los personajes urbanos del ochenta ${ }^{22}$. El joven es hijo de una familia federal y tiene la posibilidad de codearse con los grupos rosistas y ganar su confianza; milita entre los unitarios. No es apasionado ni tiene las cualidades románticas que caracterizan a Belgrano. Es un personaje eminentemente político, astuto, capaz de adecuarse a las circunstancias y obtener el mejor partido para los unitarios. Literariamente cumple la función de moverse entre los dos bandos contrarios a fin de que podamos saber de cada uno. Es el personaje que más se desplaza por la ciu* dad $y$, con sus itinerarios, nos permite conocerla mejor ${ }^{23}$.

La ciudad degradada es aquélla en donde predominan los federales. Si los unitarios son refinados, cultos, bondadosos, diplomáticos, astutos, bellos, los rosistas son torpes, bárbaros, desagradables, irracionales, sensuales, ignorantes. Al narrador le

${ }^{22}$ Véase al respecto mi artículo "Buenos Aires en la imaginación del 80. El teatro como paradigma", Letterature d'America, Roma, 1983, núm. 16, 89-21.

${ }^{23}$ Bello es el "héroe mediocre" bien definido por LuKács en The historical novel (Merlin Press, London, 1962, pp. 33-37). Queda por ver si 'Amalio. es una novela histórica. Coincidimos con Anderson Imbert en que la contemporaneidad de los hechos no permitió que Mármol adoptara una perspectiva imparcial frente a los eventos que narra. En Scott, por ejemplo, hay un rasgo fundamental de este tipo de novela, y es que las grandes transformaciones históricas son presentadas como revoluciones de la vida popular. En Scott, la interacción de los de "arriba" con los de "abajo" constituye el tejido de sus novelas y la acción histórica es lograda por los cambios en los estratos populares. Subrayemos que este aspecto no está presente en Mármol quien niega, también, la posibilidad de una acción consciente por parte de las clases desposeídas. Si Scott procura desplegar la "grandeza humana" que en los cambios históricos se evidencia en representantes de bandos sociales contrarios, dando lugar a una atmósfera épica, Mármol, intencionalmente, pone de manifiesto tan sólo la grandeza del grupo unitario. De allí que para la configuración de los personajes le sean más útiles las técnicas del folletín que las de la novela histórica. El escritor argentino carece de aquellas cualidades literarias que volvieron a Scott, Balzac o Tolstoi escritores realistas a pesar de sus perspectivas sociales. No obstante, Mármol mantiene ese personaje "mediocre", que también aparece en las novelas de Scott, y que se caracteriza por una inteligencia práctica, fortaleza moral, decencia y una cierta capacidad de sacrificio, pero que nunca llega a conformarse en una gran pasión. Daniel Bello es, pues, el personaje enlace, cuya clarividencia política le permite alternar con el narrador las digresiones sobre la situación que se vive en Buenos Aires. 
resnlta molesta la insolencia con que el pueblo se relaciona con la "geve decente"; sucede que los grupos populares que provenían de la campaña no solían tener oficio, ya fuese por su condición re parias, ya por la facilidad de mínima supervivencia que había en el campo, lo que los volvía menos dependientes de los sectores en buena posición económica. Considera, además, que a causa del gobierno rosista se "ha perdido el equilibrio de las clases" (IV, 5, p. 271). Buenos Aires ha cambiado su composición demográfica; ahora toda ella resulta un gran "matadero": los nuevos habitantes forman "esa multitud oscura y prostituida que él [Rosas] había levantado del lodo de la sociedad para sofocar con su aliento pestífero la libertad, la justicia, la virtud y el talento" (I, 5, p. 44, corchetes míos).

No se escatiman adjetivos negativos para retratar la clase popular que apoya a Rosas, pero en ella, aparte de observar su variedad racial, Daniel Bello hace una distinción:

Sólo hay en la clase baja una excepción, y son los mulatos, los negros están ensoberbecidos, los blancos prostituidos, pero los mulatos, por esa propensión que hay en cada raza a elevarse y dignificarse, son casi todos enemigos de Rosas porque saben que los unitarios son gente ilustrada y culta, a la que siempre toman ellos por modelo (I, 2, p. 18).

Los mulatos, pues, no presentan la hostilidad y el desprecio de otros sectores pauperizados de la aldea ante el ciudadano, desprecio que resulta del traslado de una visión del mundo campero al interior de la cultura urbana porque, como afirma el narrador:

El hombre de la ciudad monta mal a caballo; es incapaz de conducirse por sí solo en las llanuras desiertas; más incapaz aún de procurarse en éstas la satisfacción de sus necesidades y, por último, el hombre de la ciudad no sabe prender un toro al certero lazo de los gauchos, y tiene miedo de hundir un cuchillo hasta el puño en la garganta del animal, y no sabe ver sin agitación que su brazo está empapado en los borbotones de sangre (IV, 8, pp. 284-85) ${ }^{24}$.

${ }^{24}$ Frase que parece tomada de Facundo. Refiriéndose al hombre de campo, dice Sarmiento que "es preciso ver estas caras cerradas de barba, estos semblantes graves y serios, como los de los árabes asiáticos para juzgar del compasivo desdén que les inspira la vista del hombre sedentario de las ciudades, que puede haber leído muchos libros, pero que no sabe aterrar un toro bravío y darle muerte, que no sabrá proveerse de caballo a campo abierto, a pie y sin el auxilio de nadie, que nunca ha parado un tigre y recibídolo con el puñal en una mano y el poncho envuelto en la otra para meterle en la boca 
El relator pone también de manifiesto el menosprecio del hom bre letrado de Buenos Aires frente al pueblo que logra participar en los festejos que ofrece el gobernador. Sin embargo, en esa visión degradada del ambiente popular, se plantean algunas generalizaciones para todos lo habitantes de la aldea, de las que siempre se separa el yo hablante, cuando éste es el narrador o un personaje identificado con él:

[Y]o soy porteño; hijo de esta Buenos Aires, cuyo pueblo es, por carácter, el más inconstante y veleidoso de esta América; donde los hombres son, desde que nacen hasta que se mueren, mitad niños y mitad hombres, condición por la cual buscaron el despotismo por el gusto de hacer una inconstancia a la libertad (II, 9, p. 150).

No obstante, predomina una marcada sensación de extrañamiento en el punto de vista de la novela, frente a los grupos rosistas, particularmente cuando se describe una situación en la que se exige un cierto ceremonial o un código de maneras. Del baile anual del 25 de mayo se dice que "un no sé qué[...] se encontraba de ajeno al lugar en que se daba la fiesta, y a la fiesta misma; es decir, se veían con excesiva abundancia esas caras nuevas, esos hombres duros, tiesos y callados que revelan francamente que no se hallan en su centro cuando se encuentran confundidos con la sociedad a que no pertenecen" (II, 7, p. 131). Lo mismo sucede en "Escenas de la mesa", capítulo que rememora "Un castellano viejo" de Larra. Cuando se termina el baile, se pasa al comedor y allí, "un silencio apenas interrumpido por el ruido de la porcelana y los cubiertos, inspiraba un no sé qué de ajeno al lugar, y ponía en conflicto a la parte más crecida de los asistentes, en medio de ese silencio de funerales' (II, 11,p.157). La escena desemboca en lo grotesco cuando se describe la comida mostrando la parte por el todo. Los cubiertos, abstraídos de los comensa-

mientras le traspasa el corazón y lo deja tendido a sus pies" (Domingo FAUSTino Sarmiento, Facundo. Civilización y barbarie, Editora Nacional, Madrid, 1975, pp. 86-87). Sin embargo, SARMiento, a diferencia de Mármol, establece un punto de contacto entre la cultura urbana y la del campo: la música y la poesía, "dos artes que embellecen la vida civilizada y dan desahogo a tantas pasiones generosas están honradas y favorecidas por las masas mismas que ensayan su áspera musa en composiciones líricas y poéticas" (ibid., p. 95). Y agrega, "El joven Echeverría residió algunos meses en la campaña en 1840 y la fama de sus versos sobre la pampa le había precedido ya; los gauchos lo rodeaban con respeto y afición, y cuando un recién venido mostraba señales de desdén hacia el cajetilla alguno le insinuaba al oído: "Es poeta» y toda prevención hostil cesaba al oír este título privilegiado" (id.). 
les, son aún más reveladores de la rigidez y la falta de naturalidad de aquéllos:

El tenedor se levantaba del plato con una delicadeza tal, que parecía entre los dedos el fiel de una celosa balanza, pronto a inclinarse al más ligero accidente. El pedacito de ave o de pastel era llevado a los labios con la misma delicadeza con que una persona de buen gusto lleva a la nariz una delicada "flor del aire", y los indecisos labios lo tomaban tiernamente, después que los ojos habían girado a derecha e izquierda para ver si alguien notaba el pecado capital de comer cuando se está para eso en la mesa (II, 11, pp. 157-158).

Así, pues, Mármol admira la destreza y valentía de los jinetes de la pampa y reconoce la incapacidad del hombre de ciudad para defenderse en ella, pero cada uno debe estar en su lugar. La ironía, la hipérbole y ios toques grotescos ponen de manifiesto el desasosiego de Mármol frente al llamamiento popular del gobernador de Buenos Aires y la adhesión que las masas le ofrecían. Pero el cuadro del baile y de la mesa hiperboliza una situación cuya verdad - que los federales se manejaban con un código de maneras que no conocían - es relativa, ya que la oligarquía federal no era diversa de la unitaria, incluso dentro de la novela misma: pensemos en la familia Bello que, exceptuando a Daniel, era rosista.

En otros personajes de la ciudad literaria el referente es la condensación de elementos culturales e ideológicos que estaban en juego en aquel tiempo y que, por lo tanto, constituye, pero también deforma la realidad histórica ${ }^{25}$. Son los personajes que podríamos llamar "híbridos", de origen campesino, y que por su asociación con la gente pudiente - y sobre todo unitaria- son vistos como "civilizados". Fermín era "un joven de dieciocho o veinte años, de cabellos y ojos negros, de una fisonomía inteligente y picaresca y que, a pesar de sus botas y corbata negra, estaba revelando cándidamente ser un hijo légitimo de nuestra cam-

25 Véase, de T. E. Lewis, "Notes toward a theory of the referent", PMLA, 94 (1979), 459-475. Lewis trata de vincular el concepto semiótico de referente definido por U. Eco, con la noción marxista (althusseriana) del mismo. Observa que el concepto de "unidad cultural" de la semiótica, es vinculable al de "unidad ideológica" del marxismo. El referente literario resulta así una construcción dialéctica determinada por la relación entre la unidad cultural-ideológica, considerada como el "producto bruto" y una nueva unidad producida por el trabajo textual. 
paña: es decir, un perfecto gauchito, sin chiripá ni calzoncillos" (I, 2, p. 22). A primera vista resalta la ambivalencia del retrato: de nada vale que el muchachito se vista "de ciudad", porque continúa siendo una figura trasplantada del campo, a la que se niega la posibilidad de asimilarse al medio urbano: será siempre visto - aunque se ponga corbata y botas - como un hombre de afuera, y la condición de su idiosincracia permanece ambigua dentro de la lógica del relato. Cabe preguntarnos, ¿por qué legítimo? ¿cuáles son los hijos "bastardos" del campo? ¿los gauchos de Rosas? La pregunta queda suspendida, aunque se infiere que la legitimidad de Fermín reside en haberse sometido a un hombre de la ciudad: Fermín, criado de Bello, o Pedro, al servicio de Amalia, no se identifican con ningún espacio real; no pertenecen a ningún grupo social, sólo a sus amos.

\section{LAS MANSIONES: SU FUNCIÓN EN EL MELODRAMA}

Los sitios en los que Mármol contrapone a los divididos habitantes de Buenos Aires son la casa de Rosas (I, 4,) y la habitación de Amalia $(I, 2)$, que funcionan alegóricamente dentro del relato. Por medio de los objetos, del decorado, la iluminación y la forma de comportarse de los ocupantes, representan otra cosa ( $\alpha \lambda \lambda$ os): dos grupos del cuerpo social.

Las residencias establecen encontradas posibilidades de "ser" de la ciudad; por medio de ellas percibimos escalas de valores que resultan paradigmas de diferentes modos de vida ciudadana ${ }^{26}$, cuyo diseño metafórico abarca toda la novela. Hernán Vidal ve este diseño dividido entre espacios públicos con grupos demoníacos y lugares privados con habitantes espirituales:

Conocida la contraposición conflictiva entre un espacio privado [el de Amalia] circundado por espacios públicos que amenazan [casa de Rosas, restaurantes, cafés, calles] se puede observar que el capítulo I de la Primera Parte sugiere al lector que la entrada a Buenos Aires en esa época crítica equivale a una peregrinación por un laberinto demoníaco y desorientador en el que pululan monstruos grotescos. Su portal está marcado por la obscuridad, la traición, la violencia y la muerte. Sin embargo, en este laberinto habi-

${ }^{26}$ Gaston Bachelard ha señalado que "la maison est une des plus grandes puissances d'intégration pour les pensées, les souvenirs et les rêves de l'home', en La poétique de l'espace, Presses Universitaires, Paris, 1958, p. 26. 
tan seres cercanos a la divinidad que luchan porque la espiritualidad domine algún día sobre los cuerpos degradados por el demonio. Los seres superiores encuentran refugio y convivencia amorosa en los espacios de Amalia, ocultos en el vientre de una ciudad encanallada ${ }^{27}$.

Buenos Aires aparece pintada por Mármol con tonos sombríos y rojizos. Los colores extremos denotan la perspectiva partidaria de Mármol y el tratamiento folletinesco acompaña formalmente a su sistema rígido de representación. Las descripciones en el folletín procuran definir el mundo, más que representarlo; la descripción negativa de un lugar sirve para introducir acciones o personajes malos, y un lugar espléndido es indicador de una acción o un personaje bueno ${ }^{28}$. En Amalia la ciudad cumple la función de proveer la ambientación subyacente de un clima de terror. Los lugares más adecuados para situar esa tensión político-social son los callejones oscuros y fangosos, las casas de los federales cuyos zaguanes presentan bultos humanos que en la oscuridad no se diferencian de los perros guardianes, las calles empedradas y vacías en las que por la noche resuenan los cascos de los caballos de la Mazorca.

La casa de Rosas tiene la cualidad de sótano, según la fenomenología de Bachelard: es la entidad oscura, movida por fuerzas subterráneas, y en ella predomina una coloratura entre el negro y el rojo, que acompaña a las figuras goyescas de la guardia del Restaurador. La vivienda se configura por medio de la inversión. Allí se duerme vestido, se establece la comisaría de campaña en lo que es una sala, se trabaja cuando es de noche, porque Rosas, "como invertía los principios políticos y civiles de una sociedad, invertía el tiempo, haciendo de la noche día para su trabajo, su comida y sus placeres"' (I, 4, p. 37). Asimismo, indirectamente se señala que los custodios de la casa son guardianes del "desorden" porque tienen "cierta expresión en la fisonomía que da los primeros indicios a los agentes de la policía secreta de París o Londres, cuando andan a la caza de los que se escapan de galeras, o de forajidos que han de entrar en ellas' (I, 4, p. 33). La frase denuncia lecturas europeas de aventuras o de incipiente trama detectivesca. Asimismo Mármol expresa aquí su visión del

${ }^{27}$ H. Vidal, “Amalia: melodrama y dependencia”, I\&L, 2 (1977), p. 64. Los corchetes son míos.

${ }^{28}$ Véase de J. Epple, "Notas sobre la estructura del folletín”, CuH, 120 (1980), 147-156. 
mundo: los centinelas de Rosas tienen una expresión contraria a la función que deberían cumplir si la experiencia rosista no fuese una “inversión"' histórica. Sin embargo, no existe, ni en la realidad degradada que se narra, ni en la situación virtual a la que se aspira, una imagen concreta de los vigilantes del Orden. La que se ofrece proviene de los dos países europeos con mayor predominio político y económico en Latinoamérica por aquel entonces. Mármol se apoya en las dicotomías, dejando vacío el lugar de la síntesis. Como señala Viñas, "lo que apela a Europa se valida en detrimento de lo conectado con lo inmediato. El Bien y el Mal. Mármol apuesta al bien identificándose con lo europeo"'29.

La claridad y la seclusión caracterizan las casas unitarias de Buenos Aires. Son ámbitos cerrados pero llenos de luz. Y en lo de Amalia, lo primero que salta a la vista es la acumulación de comodidades provenientes de países europeos o asiáticos: el tapiz de Italia, la cama francesa, las tapafundas de Cambray, una colgadura de gasa de la India, algodones empapados en agua de Colonia, jarras de porcelana francesa, una bandeja del mismo material y un sillón de paja de la India. Sólo provienen de Latinoamérica dos pebeteros de oro peruano. El gusto del personaje por metales preciosos como el oro y la plata, y por materiales valiosos como marfil, seda, nácar, ébano, cristal, sándalo, alabastro, porcelana, mármol, damasco, nos sitúa en la atmósfera de una ciudad para unos pocos, los capaces de disfrutar los objetos transformados en fetiches. Estos rasgos parecen augurar la actitud literaria que prevalecerá en el período modernista.

Nada hay en el hogar de Amalia que nos haga pensar en la discordancia. El ambiente tibio y perfumado concierta con el amor y la hermosura. Por eso se diría que la habitación de Amalia, "el solitario templo de una belleza", es el único sitio en donde perdura la condición religiosa de la antigua polis, porque en el Buenos Aires de 1840 no había " quién velase por la santidad del templo" (IV, 5, p. 272).

Si la vivienda del gobernador es oscura y abierta y la de la viuda, llena de luz y cerrada, la contradicción intrínseca en cada par de términos revela su cualidad ideológica, lo cual entra en relación con el contexto social y la situación histórica, pues lo "abierto"' de la casa de Rosas corresponde a la relativa movilidad que se había producido bajo su gobierno; en cambio, lo "cerrado",

${ }^{29}$ D. Viñas, "Mármol, los dos ojos del romanticismo", en Recopilación de textos..., p. 284. 
de la mansión de Amalia no sólo hace referencia a la cualidad "privada", sino también a la actitud que los grupos unitarios hegemónicos tenían con la pequeña burguesía y las clases populares, cuyos desplazamientos percibían como una amenaza concreta. El uso de "luz" y "oscuridad" forma parte de un esquema que resulta análogo al de "civilización y barbarie". También los espacios rosistas pueden estar iluminados, pero siempre de manera distinta que el hogar de Amalia. Si en éste la luz del sol está mediatizada por cortinas de muselina y la luminosidad armoniza con la atmósfera de la casa, en el gran salón de baile presidido por Manuelita Rosas se destaca la "abundancia" de candiles y de brillos: "El oro de las casacas militares y los diamantes de las señoras resplandecían a la luz de centenares de bujías, malísimamente dispuestas pero que, al fin, despedían una abundante claridad", (II, 7, p. 13). El exceso es, en la novela, una manera de "estar a tono" de los rosistas y aparece en la gran mayoría de los sintagmas que los caracterizan.

\section{LA CIUDAD-DESIERTO}

Durante el gobierno de Rosas el paisaje urbano está cubierto por una atmósfera de tensión y silencio: "El monótono ruido de nuestras pesadas carretas, dirigiéndose a los mercados públicos, el paso del trabajador, el canto del lechero, la campanilla del aguador, el martilleo del pan entre las árganas; todos esos ruidos especiales y característicos de la ciudad de Buenos Aires al venir el día, hacía ya cuatro o cinco que no se escuchaban'. La imagen se redondea al final del párrafo: "Era una ciudad desierta; un cementerio de vivos"' (IV, 1, p. 246).

El cuadro de la villa deshabitada se enlaza con la perspectiva del escritor expatriado; se sugiere así que la mayoría de la población está en contra de Rosas y por eso emigra o se oculta. Por lo que alcanzamos a saber a través de Facundo, Sarmiento tenía, a veces, una idea diversa de lo que era la ciudad por esos mismos años. Su libro nos dice que "Facundo desaparece en el torbellino de la gran ciudad"' (p. 172); el sanjuanino presenta a Buenos Aires como una aldea que ofrece a sus habitantes múltiples estímulos y agitación urbana.

Cuando Mármol describe los sectores populares, de ningún modo la ciudad ofrece un aspecto deshabitado:

La comunidad de la Mazhorca, la gente del mercado y sobre 
todo las negras y mulatas que se habían dado ya carta de independencia absoluta para defender mejor su madre causa, comenzaban a pasear en grandes bandadas la ciudad y la clausura de las familias empezó a hacerse un hecho[...]. Los barrios céntricos de la ciudad eran los más atravesados en todas direcciones por aquellas bandadas, y las confiterías, especialmente, eran el punto tácito de reunión (V, 1, p. 334).

Es que la soberbia e ilustrada aldea de la época rivadaviana ha sido ruralizada por grupos federales; desde el punto de vista de los unitarios más intransigentes, Buenos Aires está desierta por el terror, ha sido invadida por la pampa. Esta idea se repite una y otra vez: "No eran más que las doce de la noche, pero la ciudad estaba desierta[...]. De aquel alegre y bullicioso pueblo de Buenos Aires, cuya juventud en otro tiempo esperaba con impaciencia la noche para dar expandimiento a su espíritu, ávido de aventura y de placeres, no quedaba ya un solo vestigio' (IV, 16, p. 324).

La ciudad desierta sugiere, asimismo, la idea de una ciudaddesierto. Esta imagen deriva, a mi parecer, de una aposición de las usuales antípodas del período: el campo ${ }^{30}$ y la ciudad. Aposición que - recalco- no es síntesis, pues degrada en su fusión aparente la importancia y el carácter de cada uno de los términos de la antinomia. Vale esto para la visión negativa que Mármol ofrece de la dictadura rosista; sin embargo es, al mismo tiempo, la carencia resolutiva de la perspectiva dependiente del escritor.

\section{CONCLUSIÓN}

Buenos Aires es, en Amalia, una imagen más concreta y acabada que la de El matadero o Facundo. El que se logren captar numerosas facetas de la aldea a orillas del Plata es también consecuencia del uso del género novelístico, apto para configurar con mayor complejidad un tema.

Como acabamos de ver, en Amalia hay detalles cotidianos en los que se enfocan ángulos de Buenos Aires de modo bastante realista; pero la motivación general del autor da lugar a una particular estructura novelística en la que cada motivo funciona crítica-

${ }^{30}$ Recuérdese que la conquista de la tierra a los indios se llamó "campaña al desierto", aunque buena parte de ese territorio constituyera la fértil pampa húmeda. 
mente respecto de la ciudad bajo el gobierno de Rosas. Toda Amalia es una gran alegoría del estado de la aldea en 1840. Y ésta, o los personajes que la habitan, son descritos por una suerte de predicados invariables, que tienen que ver más con una intención ideológica que con un gesto mimético.

El cuadro urbano de la novela pone de manifiesto el conflicto existente entre las relaciones sociales de la ciudad y las del campo. Para los proscriptos, Rosas es el culpable de que Buenos Aires no sea ya la "Babilonia americana", olvidando o desconociendo que la sociedad urbana de Latinoamérica no podía alcanzar el modelo de las capitales europeas mientras siguiese siendo dependiente de ellas. Luego de la emancipación de España, Buenos Aires pasará a constituir la periferia del imperio inglés. La ciudad comercial y patricia del diecinueve posee un carácter colonial en el que aún no existe una verdadera división del trabajo con el campo. Todo esto permite conjeturar que la imagen virtual que Echeverría, Sarmiento y Mármol superponen a la verdadera Buenos Aires es tan sólo una idea de urbe, es más un proyecto que una realidad.

Las categorías utilizadas por ese período, "civilización" y "barbarie", no tienen cualidad operativa porque son concebidas como contenidos que se limitan a registrar dos niveles culturales (como "ricos" y "pobres", en donde sólo se constatan dos niveles económicos diversos). La capacidad funcional de, por ejemplo, "explotadores" y "explotados", reside en que estos conceptos se refieren a un sistema de reglamentación de las relaciones productivas, a la formación de plusvalía y a la valoración de tal código, es decir, al que sustenta la explotación. Para lograr la misma funcionalidad en la antinomia sarmientina habría que suplantar "civilización" por cultura hegemónica y "barbarie" por cultura subalterna, marginal o periférica y, de esa manera, estaría implícito el modo de relación entre una y otra. Sin embargo, durante el período cuyos conflictos se tratan en Amalia, no se podía hablar de "cultura hegemónica" adjudicándola a grupos y procesos de manera categórica, porque el poder económico era disputado no sólo entre la burguesía comercial y la ganadera - de un origen más reciente - sino también entre sectores de Buenos Aires y de las provincias. La lucha política agudizaba los conflictos entre el interior y la ciudad-puerto, entre liberales y conservadores y se observaba, además, en las ligas provinciales. No se podía hablar de un definido dominio económico y político dentro del país; en cambio, efectivamente existían grupos poderosos y subordinados desde un punto de vista social: las masas rurales y la pequeña burguesía o sectores suburbanos se encontraban en una posición mar- 
ginal respecto al debate de intereses señalado más arriba.

En aquel momento, a mi parecer, estaba conformándose el concepto mismo de hegemonía, y se lo discutía contraponiendo, en un mismo nivel, dos formas diversas de enfrentar su proceso constitutivo. J. L. Romero hace notar que el mayor problema de ese período histórico fue el suponer que se estaba hablando de dos doctrinas, de dos formas de pensamiento político, pero que, en realidad, lo que estaba en juego era, por un lado, la línea del pensamiento orgánico, democrático, doctrinario y liberal y, por el otro, la línea de la democracia inorgánica que se manifestaba por medio del sentimiento federal y autoritario ${ }^{31}$.

Creo que los conceptos de "civilización" y "barbarie" pueden llegar a ser operativos dentro del tema literario de la ciudad, si concebimos a la "civilización" como forma, o el código que le da significación - interpreta, selecciona - al contenido, la "barbarie"'. Los escritores de la generación del 37 toman de Europa la forma típica del romanticismo: la antítesis -observable en la estructura folletinesca, en los héroes espirituales y demoníacos-, para expresar contenidos americanos: el malón, el matadero, los caudillos, la anarquía, la naturaleza salvaje, la dictadura. Formas "civilizadas" y contenidos "bárbaros" se articularán de manera particular en cada escritor, dependiendo de su enfoque de la realidad. Dependerá del matiz ideológico de la tesis personal de cada autor el que la síntesis se logre o no.

Algunos intelectuales aúnan a una perspectiva empírica de la realidad argentina elementos socialistas y liberales que recogieron de Europa; otros - como Mármol - tienden a vincularse mejor en una actitud conservadora. Ambos sectores intentan "el diagnóstico de las confusiones morales de la tiranía apoyándose en una etapa crítica - 1840, crisis dentro de la crisis-, para condenar el aprovechamiento rosista de ciertas modalidades nacionales' '32. Este análisis de la compleja situación del gobierno en un momento álgido de la vida del país, no pudo no dejar secuelas en la representación de la realidad social. Así es como se produce una suerte de reduccionismo: en vez de ser el contenido complejo de lo real el que sugiere la modalidad del discurso literario, es la forma del mismo la que se impone sobre los contenidos históricos y sociales.

Asimismo, a lo largo de las polémicas sobre la pertenencia o

31 J. L. ROMERO, op. cit., parte $2^{\mathrm{a}}$.

32 J. C. Ghiano, "Protagonistas y espacios en Amalia", en Recopilación de textos..., p. 301. 
no al movimiento romántico, se percibe otra contraposición que se vincula con la tematología y, por ende, con el asunto de la ciudad. En 1839, Alberdi afirma: "No somos ni queremos ser románticos", y para demostrarlo contrapone a los motivos literarios del romanticismo (la perla, la lágrima, la muerte, la bruja, etc.) otros hacia los que expresa su adhesión (la patria, la humanidad, el progreso, la libertad, las pasiones, la esperanza nacional, etc. $)^{33}$. En realidad, estos últimos asuntos no estaban excluidos del romanticismo, sino que su carácter más abstracto los relaciona con un ámbito que se extiende más allá de la literatura y que puede abarcar lo ideológico, lo filosófico, lo histórico. En suma, se puede afirmar que Alberdi opone a motivos románticos, temas románticos; es decir, contrasta asuntos cuyo referente es inmediato, con otros que hacen a una generalización de referentes. Sobre este antagonismo entre motivos y temas se basa la imagen literaria de Buenos Aires en Amalia.

Los motivos de la cotidianeidad porteña localizan temporal y espacialmente el tema de la ciudad dentro de la novela. Sin embargo, Amalia pertenece al corpus de textos de los proscriptos en donde el asunto urbano se inscribe dentro de un esquema resultado de anteriores generalizaciones de un conjunto de referentes. El tema de la ciudad se apoya, como ya dijimos, sobre el esquema "civilización $v s$. barbarie", cuya elaboración se conecta con la discusión europea sobre el concepto de civilización en el siglo dieciocho, pero cuyo trasfondo histórico - la emergencia de las ciudades industrializadas en el Viejo Mundo- nada tenía que ver con la situación latinoamericana de mediados del diecinueve. El esquema, de carácter filosófico e ideológico, pretende englobar y dar coherencia a los motivos de índole empírica - costumbrista e histórica. La oposición sarmientina suministra un sentido a los motivos urbanos, ordenándolos en dos polos.

Los motivos representativos de la vida urbana aparecen sintagmáticamente estereotipados: los connotados positivamente se refieren a la aldea del pasado o al contexto europeo de la atmósfera de las casas unitarias. Los asuntos que se refieren a la ciudad del presente, en cambio, pasan a constituir el paradigma de signo inverso, el de un espacio no urbano, símbolo del "desierto" y la "barbarie".

De la contraposición de motivos y el tema / Idea de Ciudad, surgen - particularmente en la obra de Sarmiento y Echeverría-

${ }^{33}$ J. B. Alberdi, "Al anónimo del Diario La tarde", en La moda, Buenos Aires, 6 de enero de 1936. 
imágenes que permiten establecer asociaciones utópicas (las ciudades como islas en medio de la pampa como mar). En cambio, el sentido utópico no está presente en la novela de Mármol por la simple razón de que, en su imagen de Buenos Aires - en la aposición "ciudad-desierto" -, no presenta una solución imaginaria de las contradicciones históricas ${ }^{34}$.

Gecilia Graña

Università degli Studi di Verona

${ }^{34}$ Según Louis MARIN, "el discurso utópico ocupa la plaza vacante - históricamente vacante- de la resolución histórica de una contradicción", en Utópicas. Juegos de espacios, Siglo XXI, Madrid, 1975, p. 1. 